\title{
Instructor Influence on Student Intercultural Gains and Learning during Instructor-Led, Short-Term Study Abroad
}

\author{
Christine L. Anderson, Karl Lorenz, Michael White \\ University of Minnesota - Twin Cities
}

In the United States post 9/11, there is increasing interest by the government and by institutions of higher education in educating students and citizens to more successfully navigate difference and interact in an increasingly connected world. This has led to a rise in the number of U.S. American students studying abroad especially on instructor-led study abroad programs. The Institute of International Education reported in 2011 that $61 \%$ of schools in their annual survey added new instructor-led programs (Institute of International Education, 2011). The increase in US American instructors taking students abroad focuses attention on the role of the instructor to aid students' development, cultural competency, and ability to make meaning of their new environment. The goal of this study is to investigate the influence of the instructor on student intercultural gains and learning during instructor-led study abroad.

\section{Statement of the Problem}

For many students to gain the skills required to learn about themselves, shift perspective, and widen their worldview, certain pedagogical approaches and support systems are necessary (Bennett \& Bennett, 2003; Pedersen, 2009b; Vande Berg, Quinn, \& Menyhart, 2012; Younes \& Asay, 2003). If students' assumptions about what they are experiencing in a new context are not guided or critically reflected upon there is a risk that they will be unable to understand the new frame of reference and turn back to prior traditional ways of knowing, and thus "create imaginary meanings" made up of projection and rationalization (Mezirow, p. 3, 2000). A lack of intentional engagement could lead to the reinforcement of stereotypes or inappropriate behavior issues abroad (Pedersen, Cruz, LaBrie, \& Hummer, 2011; Pedersen, Neighbors, Lee, \& Larimer, 2012). John Dewey (1916) wrote that experiences can be "mis-educative" just as easily as they can be educative. As instructors bring students abroad in greater numbers it is imperative that instructors are able to implement productive pedagogical approaches and design their programs for optimal cultural sensitivity gains.

Education abroad literature often highlights the positive impact of study abroad such as a rise in students' global perspective, ability to learn, world mindedness and cross-cultural awareness and sensitivity (Bakalis \& Joiner, 2004; Cisneros-Donahue, Krentle, Reinig \& Sabol, 2012; Douglas \& Jones-Rikkers, 2001; Kitsantas, 2004; Rexeisen \& Al-Khatib, 2009). These desirable student outcomes are now often listed as student learning goals for higher education in general. Meacham and Gaff (2006) report that three of the twelve most common learning goals in campus mission statements are: "appreciating diversity"; "building communities that acknowledge and respect difference"; and "international and global understanding" (p. 9). This push for more students to go 
abroad is mirrored in the congressionally appointed Commission on the Abraham Lincoln Study Abroad Fellowship Program's goal to have one million U.S. students study abroad by 2020, with a key outcome for students to become "internationally competent" (NAFSA, 2005, p. iv).

These initiatives and desired student outcomes often infer that the act of going to another country in and of itself gives a student a new global awareness or greater cultural competence. If unchallenged, this inference may lead institutions to send instructors abroad in greater numbers without first ensuring that instructors have been prepared by gaining an understanding of the pedagogy and mentoring that is necessary for these intercultural gains to occur. The concern within the study abroad community is that the act of sending more and more students abroad is not on its own sufficient to prepare interculturally competent students (Engle \& Engle, 2012; Pedersen, 2009b; Vande Berg et al., 2009; Vande Berg-, et al., 2012). Bennett (2008) states, “... cultural contact does not necessarily lead to competence. The mere intermingling of individuals in intercultural contexts is not likely to produce, in itself, intercultural learning" (p. 17).

There is also debate within the education abroad community on the importance of program duration to increase intercultural learning. There are multiple studies that compare longer-term study abroad against shorter duration study, that find intercultural learning is not as strong on shortterm study abroad (Dwyer 2004; Medina-López-Portillo, 2004; Stephenson, 2002; Vande Berg, Connor-Linton, \& Paige, 2009). Although these studies focus on short-term study, they do not focus on the instructor-led model. There is a small set of studies that show that intercultural learning and student development are possible on instructor-led programs (Anderson, Lawton, Rexeisen, \& Hubbard, 2006; Lorenz, White, \& Anderson, 2012; Nam, 2011; Pedersen, 2009a) with only the Pedersen study focusing on the role of the instructor in facilitating student intercultural growth.

Recent research within the field of education abroad has shown that cultural mentoring and cultural interventions are effective methods for furthering student intercultural learning on longer term programs (Engle \& Engle, 2012; Pedersen, 2009b; Vande Berg et al., 2009; Vande Berg, Quinn, \& Menyhart, 2012). Some of these studies have shown that without cultural interventions valued program features such as integrated classes, longer program duration, and homestays, may not further intercultural learning and may cause regression in some students (Pedersen, 2009a; Pedersen, 2009b; Vande Berg et al., 2009). This deeper understanding of the importance of the mentor within the intercultural learning scheme makes the instructor-led program model a more viable option for this learning to occur, if the instructor is willing and able to facilitate the learning.

\section{Purpose of the Study}

Earlier research we conducted from 2012-14 indicated that significant intercultural learning can happen on short-term (three week), instructor-led study abroad programs (Lorenz, White, \& Anderson, 2012). Our goal with the current paper is to further articulate and assess the relevance of a key finding from that research: intentional instructor engagement with intercultural content while in situ is a critical component in fostering student intercultural growth. Our prior research targeted students participating in instructor-led study abroad classes to determine if it was possible to generate sustained intercultural growth as measured by the Intercultural Development Inventory (IDI) and post-travel questionnaires in such a short time. This question is particularly relevant 
inasmuch as the growth of instructor-led programs has accelerated to meet the demands of providing ever-greater numbers of students with opportunities to study abroad.

Our earlier research engaged 27 classes traveling to diverse locations globally (e.g., Thailand, Switzerland, Peru, Florence Italy, Kenya) by employing various interventions to determine which, if any supported student intercultural developmental gains. We employed two specific models of incorporating cultural learning content and maintained a control group. The control group (Chart 1, Appendix A) was offered a basic introduction to study abroad. Such pre-departure presentations are typically offered prior to study abroad and include content on how to be safe, change money, understand university conduct codes and travel as a group. A second group (Chart 2, Appendix A) of classes additionally incorporated a pre-departure introduction to concepts of intercultural development and awareness that included a presentation on Hammer's Intercultural Development Continuum (based on Bennett's Developmental Model of Intercultural Sensitivity), a group feedback session of their group IDI results with a reflection exercise on where they placed themselves in their development relative to the class distribution. Finally, they were provided an introduction to tools they could employ while abroad to intentionally engage the cross-cultural challenges they encountered. Instructors in these classes were coached on the stages of intercultural development articulated in the IDI and prepped on conducting debrief sessions with students while in country. In these debrief sessions, students were encouraged to surface and reflect on the demands of intercultural learning they experienced as they manifested. The third group of classes (Chart 3, Appendix A) followed the protocol above and added an individual IDI feedback session for each student prior to departure.

Students in the control group demonstrated little or no intercultural growth in their post IDI results. In fact, there was frequently a significant regression in their developmental orientation, possibly indicating a retreat to employing stereotypes or experiencing simple disinterest when confronted with the challenges posed by cultural difference. It was clear that the majority of students in the control group were not able to constructively integrate the intercultural learning opportunities of study abroad in this short time. Results from the two cohorts that received additional content to better prepare them for the cultural demands of study abroad presented a very different outcome. Both groups made significant gains in their intercultural development (resulting in deeper cultural understanding, new skill formation and greater interest in additional study abroad), with the greatest and most consistent gains coming from the classes incorporating individual IDI feedback sessions. Yet, there remained some variability in outcomes between classes within these two groups. On reviewing the data, we hypothesized that this was due in large part to the investment and skill of the instructor in addressing intercultural competency issues with students in instructorled study abroad programs. As stated above, the purpose of this study is to further explore that thesis. We are also interested in addressing whether prior language study, gender, challenge of location (as defined by Hofstede's cultural dimensions in comparison to the U.S.), and interaction with host country locals influence intercultural learning, since these have been shown to impact development on semester length programs (Hofstede, Hofstede, \& Minkov, 2010).

\section{Methods}

An explanatory sequential mixed methods design was chosen to quantitatively answer whether students make intercultural sensitivity gains on instructor-led study abroad using the IDI as the 
instrument, as well as investigate the influence of gender, prior language study, country challenge, instructor IDI score, and number of times the instructor has led a program. The qualitative analysis was used to more completely describe how the instructor influences students' intercultural sensitivity movement using interviews from both students and instructors.

This study investigated eight instructor-led programs taught in May and June for three and half weeks. The destinations of these programs were varied, with one in Latin America, two in Asia, one in Africa, and four in Europe. These programs were chosen as they originate from the same university, all students receive similar pre-departure information and training (including an introduction to intercultural competency development), and all program instructors received the same pre-departure information, training, and support. Each program was unique as the academic content originated from various departments with the experiential aspects tailored to each topic, the leaders had different teaching styles and philosophical approaches, and on-site support was different at each location.

Students took the IDI pre and post their experience abroad. Practical sampling was used to interview fourteen students from across the eight programs on pedagogical practices and their own development. All the instructors took the IDI prior to going abroad and had a group debrief with the offer of an individual debrief. During the group debrief, intercultural learning theory and best practices were discussed such as: reflection on developmental stages, on site debriefing on critical incidents and cultural challenges. After returning from their programs the instructors were interviewed on their approaches to teaching abroad, tools they employed, and their program design choices.

\section{Intercultural Development Inventory}

This study uses the Intercultural Development Inventory (IDI) (Hammer, Bennett \& Wiseman, 2003) which is based on Bennett's (1993) DMIS (Developmental Model of Intercultural Sensitivity). The scores and corresponding definitions are on the below table. The validity of the IDI is supported by a large research base and by multiple research studies (Hammer, 2011; Hammer, Bennett, Wiseman, 2003). Yet a criticism pointed out by Castiglioni (2013) is that the IDI is based on normal distribution across a large population and this may cause a group to maintain a larger percentage of Minimization as a developmental orientation. This was consistently the case in this study.

Table 1. IDI Worldview Description

\begin{tabular}{|l|l|l|}
\hline Orientation & Score & Description \\
\hline Denial & $55-69.9$ & Inability to construe cultural difference \\
\hline $\begin{array}{l}\text { Polarization } \\
\text { Defense \& } \\
\text { Reversal) }\end{array}$ & $70-84.9$ & $\begin{array}{l}\text { Recognition of cultural difference with an "us/them" mentality. In Defense people view their } \\
\text { own culture as superior, in Reversal they view the "other" culture as superior. }\end{array}$ \\
\hline Minimization & $\begin{array}{l}85- \\
114.9\end{array}$ & $\begin{array}{l}\text { Recognition and acceptance of superficial cultural differences. Emphasis on the similarity of } \\
\text { people and commonality of basic values. }\end{array}$ \\
\hline Acceptance & $\begin{array}{l}115- \\
129.9\end{array}$ & Acknowledges deep cultural differences in beliefs and values. \\
\hline
\end{tabular}




\begin{tabular}{|l|l|l|}
\hline Adaptation & $\begin{array}{l}130- \\
145\end{array}$ & $\begin{array}{l}\text { Acknowledges deep cultural differences in beliefs and values and can frame shift to } \\
\text { communicate and change behavior. }\end{array}$ \\
\hline
\end{tabular}

\section{Results}

\section{Pre/Post IDI Scores}

The population on this study made significant IDI gains from their mean pre-IDI score to their mean post-IDI score after an instructor-led study abroad experience. The pre- and the post-IDI score means while significantly different, remained within Minimization.

Out of 105 students $73 \%$ made positive movement on the IDI. This is a notable outcome of the study, given that there is still debate about whether or not intercultural learning can occur on instructor-led programs or programs with shorter duration. This section and the following on individual programs show that intercultural learning can occur, and often with students moving positively into a different stage which indicates more profound intercultural learning. There were notable differences between the programs (Table 4) and 13\% of the students regressed to an earlier developmental stage (Table 3).

Table 2. Total Population Mean Pre/Post IDI Score

\begin{tabular}{|l|l|l|l|}
\hline IDI & $\mathbf{N}$ & Mean (SD) & Sig. \\
\hline Pre IDI Score & 105 & $90.4(13)$ & .000 \\
\hline Post IDI Score & 105 & $97.1(17.6)$ & \\
\hline
\end{tabular}

Table 3. Total Population IDI Movement in Percentages

\begin{tabular}{|l|l|}
\hline $28 \%$ & Positive movement to another stage \\
\hline $73 \%$ & Total positive movement \\
\hline $13 \%$ & Regression to another stage \\
\hline $27 \%$ & Total negative movement \\
\hline
\end{tabular}

Table 4. Mean Pre to Post IDI Change Score by Program

\begin{tabular}{|l|l|l|l|l|l|l|}
\hline PROGRAM & $\begin{array}{l}\text { N OF } \\
\text { STUDENTS }\end{array}$ & $\begin{array}{l}\text { PRE IDI } \\
\text { (SD) }\end{array}$ & $\begin{array}{l}\text { POST IDI } \\
\text { (SD) }\end{array}$ & CHANGE & Sig. & $\begin{array}{l}\text { TOTAL POSITIVE } \\
\text { CHANGE IN \% }\end{array}$ \\
\hline Program 1 & 24 & $87.1(11.9)$ & $97.9(15.1)$ & 10.8 & .001 & $75 \%$ \\
\hline Program 2 & 16 & $94.8(10.99)$ & $107(10.8)$ & 12.2 & .000 & $94 \%$ \\
\hline Program 3 & 5 & $84.9(11.3)$ & $86.9(13.1)$ & 2 & .540 & $60 \%$ \\
\hline Program 4 & 17 & $89(16)$ & $92(20.3)$ & 3 & .355 & $47 \%$ \\
\hline Program 5 & 12 & $95.1(12.7)$ & $\begin{array}{l}106.6 \\
(106.6)\end{array}$ & 11.5 & .061 & $66 \%$ \\
\hline Program 6 & 12 & $92.5(17.4)$ & $98.6(20)$ & 6.1 & .001 & $92 \%$ \\
\hline Program 7 & 8 & $88.9(8.1)$ & $87.6(13.3)$ & -1.3 & .753 & $50 \%$ \\
\hline Program 8 & 11 & $88.6(11.4)$ & $89.6(15.4)$ & 1 & .780 & $45 \%$ \\
\hline
\end{tabular}


Pre to Post IDI Score Movement and Stage Change by Program

The variation in program population size makes program comparisons challenging, however some trends are evident. Ideally intercultural sensitivity gains allow students to achieve a perspective shift that not only enhances their understanding of culture, but guides them to a different perspective altogether. The three programs that showed the greatest gains in pre- to post-IDI mean score showed notable positive movement to another stage: Program 1 had $42 \%$ forward movement to another stage; Program 2 had 38\% forward movement to another stage; and Program 5 had 42\% forward movement to another stage. These results represent significant intercultural sensitivity gains taking place on these three and half week programs. The programs with lower student pre- to postIDI gains showed minimal movement to the next stage. Program 3, 7 and 8 had $0 \%$ forward movement to another stage; Program 4 had, 29\% forward movement to another stage; and Program 6 had $8 \%$ forward movement to another stage. While the results from the high IDI gain programs show that intercultural learning is possible on instructor-led programs, the variability between the programs indicates that there are program-specific factors contributing to these intercultural gains. In order to investigate possible factors contributing to intercultural gains, regression analysis was used to interpret the predictive relationship between host-country culture, students' host-country language level, gender, major, and leaders' IDI score against student mean pre- to post- IDI change score. These variables were chosen based on research done largely on semester length programs. Unexpectedly, no significance was found for any of these variables' ability to predict a student's IDI movement (Table 5). These results suggest that more research needs to be done on the instructorled model to investigate what variables most impact students. The data in the above section discussing how students moved along the IDI shows there is a large difference in movement trends between programs. The regression analysis does not explain why this is happening. We hypothesize that the biggest predictor of student gains on the IDI is the instructor's ability to facilitate students' interaction and reflection on the differences they are experiencing.

Table 5. Regression by Variable

\begin{tabular}{|c|c|c|c|c|c|c|c|c|c|}
\hline \multicolumn{10}{|c|}{ Model Summary } \\
\hline \multirow[b]{2}{*}{ Model } & \multirow[b]{2}{*}{$\mathbf{R}$} & \multirow[b]{2}{*}{ R Square } & \multirow{2}{*}{$\begin{array}{l}\text { Adjusted } \\
\text { R Square }\end{array}$} & \multirow{2}{*}{$\begin{array}{l}\text { Std. Error } \\
\text { of the } \\
\text { Estimate }\end{array}$} & \multicolumn{5}{|c|}{ Change Statistics } \\
\hline & & & & & $\begin{array}{l}\text { R Square } \\
\text { Change }\end{array}$ & F Change & dF1 & dF2 & Sig. F Change \\
\hline 1 & $.261^{\mathrm{a}}$ & .068 & .021 & 13.26495 & .068 & 1.451 & 5 & 99 & .213 \\
\hline
\end{tabular}

a. Predictors: (Constant), Country Culture Comparison, language, student gender, Major, Leader IDI

\section{Mixed Methods}

Reviewing the qualitative data obtained in this study reveals that students require in-country support and debrief opportunities to effectively engage and integrate the cross-cultural dimensions offered by study abroad. While it takes multiple skills to guide students through intercultural learning, frequent, intentional facilitated discussion about cultural challenge and interaction is crucial. The following discussion addresses some of the most salient points from our analysis on the quantitative and qualitative data. 


\section{Gender}

The gender ratio in this study is $27 \%$ males and $73 \%$ female. Nationally in 2012-13 women comprised $65 \%$ of all study abroad students (IIE, 2014). Vande Berg, Connor-Linton, and Paige (2009) found that "While the IDI scores of female participants increased significantly, the IDI scores of males in fact decreased slightly mathematically" (p. 18). In this study both the male and female mean IDI scores increased slightly at 4.3 and 6.7 respectively and the mean post-experience score for both groups remained in Minimization (Table 6).

The qualitative research does not answer why females made slightly higher gains on the IDI than males. Gender was not a factor in how students described their intercultural development or used terms that could denote an inclination towards one IDI stage over another. It may be that males' intercultural sensitivity develops better in a program structure with a high level of support.

Of note is that the interviews illustrated that females experience more harassment than the male students. Two of the female leaders were groped, along with multiple female students. One female student was propositioned by a hotel clerk, and others witnessed wife abuse in the street, which they found disturbing. This was mentioned in the interviews although there were no questions focused specifically on the female experience or sexual harassment during instructor-led study abroad. One male student described his view of the female experience as follows:

Then there was the feminine side of things that was unfair. There's more wolf calling and at night it would be a little more (long pause) there were eleven women and five males. We would always try to go in a group. There were a couple girls who were more confident and they could handle that kind of scene, otherwise we would go with the girls. Student

This quote shows the importance of the group for caretaking and support. Below are other descriptions of the harassment experienced by some females.

So she did Airbnb. She arrived and the guy checked her in and then he came back an hour later asking her for sex. She handled it pretty well. She emailed Airbnb and said this is happening I don't want to be here so they moved her to another place and gave her a voucher for a free place. She worked with a female on site on this. She told me, the student wouldn't even tell me. Instructor

... and we were traveling as a group of females and we were in the train and some of the men in there were touching us inappropriately. I wasn't one of them. That happened... it happened to me the second time. It did happen to other people more than once. Student

These occurrences could have led the students to make negative blanket assumptions about their host-countries. In the case of this study, the program that reported the most gender incidents by both students and the instructor is the program where the students made the most gains on the IDI. It is also the program where both students and the instructor talked the most about the process of debriefing and the only program where creating a "safe place" for debriefing came up. This emphasizes the importance of instructors leading programs having the ability to work with their students on an emotional level. It may also point to the need to have a woman available to talk with other female students. As explained in the above quote by the male instructor, his student chose to tell a female onsite staff member about her experience rather than him. 
Although females have shown a greater propensity for making intercultural gains than males, special attention needs to be paid by the instructor to ensure that any harassment faced by the female students is surfaced and that there is an opportunity to debrief this incident and to receive additional help as necessary.

Table 6. Mean Pre Post IDI Score by Gender

\begin{tabular}{|l|l|l|}
\hline Gender & Pre Mean IDI Score (SD) & Post Mean IDI Score (SD) \\
\hline Male & $91(12.8)$ & $95.3(17.3)$ \\
\hline Female & $90.4(13)$ & $97.1(17.6)$ \\
\hline
\end{tabular}

\section{Student Host-Country Language Ability}

Students were asked on their post-IDI survey if they spoke the host-language "not at all", "a little bit", or "well". Only 11\% of students identified as speaking their host-language well. Over half of the students or 54\% identified as speaking the host-language a little bit and $35 \%$ did not speak the language at all. Vande Berg, Connor-Linton, and Paige (2009) state that for study abroad participants, "prior language study is significantly associated with gains in intercultural competence. While increasing numbers of semesters of prior language study is not associated with higher pre-IDI scores, the amount of prior language study is correlated with the students' post-IDI scores" (p. 19).

This study found the opposite to be true. The pre-IDI scores increased slightly along with the amount of self-reported language ability. Although all three groups increase from the pre to post mean IDI scores, the group with the least amount of prior language knowledge made a larger gain of 9.3. The other two groups were similar to each other. Those with a little bit of language knowledge increased 5.5, and those who spoke the language well increased 5.3 (Table 7). All mean pre and post scores remained in Minimization, however the group with no language learning showed more significant gains than the groups with stronger language abilities. This may mean that the group with no language ability had less experience with new cultures and languages and therefore was more greatly impacted. These findings may be different than the Vande Berg, Connor-Linton, and Paige (2009) results since students on a semester program could be more impacted by language learning as they have more time in country making language engagement more critical.

None of the programs in this study made language learning a key component of the program although many included survival language classes. The program with the highest student IDI gains also reported the most time studying the host-country language. However, there is not enough evidence to suggest that this was the cause of their intercultural growth. Below is an illustration of this from the instructor's perspective followed by a student's perspective from the same program.

Then we start language. Oh my God, so essential, so necessary. I mean I would not, it just has to happen especially because the students so desperately wanted to create relationships and have that local engagement that even with the language instruction it was their biggest frustration that they could not have authentic relationships, even with the language learning because they couldn't communicate. Instructor 
Our onsite coordinator gave us the language lessons the first week we had them every day for about two to three hours. We would learn a little bit of culture with our language because you would learn an idiom and then you would learn where that comes from, what that means. We would learn a little bit about [our host country] as a society from that. Student

From a broader perspective, interaction or lack of interaction with the host-country language had a profound effect on students. This manifested in an increase in reported interest in language learning and in students changing majors or adding minors in language. Below are some examples of this from the student voice.

I'm studying political science and English, but I might add a Spanish minor now. I realized along the way that learning a language is so hugely important. Communication -if you can communicate with someone in their own language that's amazing. What that allows for interpersonal development and the connection you can have with people is phenomenal.

\section{Student}

I'm thinking of changing my Spanish minor into a major... I think Spanish is a much better fit with who I am. I'm such an interpersonal person. I still want to get a Masters in public health, but I can do that with Spanish. That would be a cool combination. Student

A strength of instructor-led programs may be that it exposes students to the need for a second language, perhaps for the first time, and increases their interest in language learning. It was also reported that experiencing not being able to speak the host country language helped students better understand the experience of non-English speaking people they have encountered in the U.S. That recognition and perspective shift may have deepened their intercultural sensitivity. A more refined study in this area may show more evidence of the impact of instructor-led programs on students' language learning.

Table 7. Mean Pre Post IDI Score by Host-Country Language Ability

\begin{tabular}{|l|l|l|l|}
\hline Host Country Language Ability & N & Pre Mean IDI Score (SD) & Post Mean IDI Score (SD) \\
\hline None & 37 & $88.4(14.3)$ & $97.7(18.8)$ \\
\hline A little bit & 57 & $90.8(11.8)$ & $96.3(16.1)$ \\
\hline Well & 11 & $94.1(14.8)$ & $99.4(22)$ \\
\hline
\end{tabular}

\section{Group Dynamic}

Group dynamic development is always important on instructor-led programs as there is so much intra-group interaction. This was especially important in high challenge destinations as students looked to each other for support. For this reason, an instructor should be intentional about creating a healthy group dynamic and this should be part of any instructor training. The two instructors that reported high group discord, both low IDI movement programs, tried but were not as skilled at this type of facilitation as the instructor of the highest IDI movement group who reported bringing the group to "community". A positive group dynamic emerged as highly important in the student interviews. Here are example quotes of from instructor interviews. The first is a high IDI movement program, the second had much weaker movement. 
I create the space by saying this is an open invitation. You can share anything. It doesn't have to be a deep dark thing. Almost always the person who goes first is the one who is really struggling and they put a lot out there and set the bar high for those who go next. And they think well if she can take a risk, I can take a risk. But sometimes, like one of my male students, he said, well I'm just so excited to be here, I'm sorry that I don't have anything to share. And I'm like "no that's fine!" Instructor

I would take the group and talk about it [their group dynamic issue]. Sometimes it was almost half the group and many were crying. For me it felt like such a waste of time, but I knew that they couldn't help it. It was about personalities. It was about, don't shush me.

\section{Instructor}

\section{Peer-to-Peer Processing}

Although peer-to-peer processing was not discussed in the literature review this content emerged strongly during analysis as important to students, therefore, it is included here.

Many students reported processing what they were experiencing with friends they met on the program. This type of debriefing on instructor-led programs can be powerful to the students, but can also be misguided, thus should be monitored by the instructor to check the pulse of the group. It can be beneficial for students to help each other to work through their realizations and discomforts that may accompany culture learning. Often in study abroad discourse the emphasis is on the students' interaction with locals. This is important and written about in detail in the HostCountry Local Interaction and Language sections. Yet, the comfort of friends made on the program emerged as very important to students. The close relationships may provide the necessary support that allows students to be able to handle all of the challenges they face in the short timeframe on these programs. Here are examples of the students supporting each other and processing together without an instructor.

I think getting closer to other people on the program helped with culture shock. When you are processing things with people who are experiencing similar things you can like bounce things off them. For me I'm an external processor. You can go out together and tackle it. Student

I think a lot of that [my ability to adapt] was because it wasn't just me, myself and I going to Kenya and studying in a Kenyan institution. It was me plus 14 other students, plus my professor, plus the on site staff. So I had a really strong support system of other Americans to help with the challenge... In the evenings you would talk even more about each person's unique experience, like I saw it like that, I thought it was actually cool. But you didn't like it so much and that's just an incredible growing experience when you can both, when we can all be at the same place and have 15 different opinions about it. Student

We just saw a cathedral. As soon as we went in the conversation was turned off. Silent. Without even saying anything we agreed to experience it totally silently. It was beautiful and we had just grown so much and learned so much about each other and talked for so long and then we did something that was also together but totally silent and just appreciated all these things that we were learning about and these paintings which were the physical form and it was really cool. Especially knowing that we were coming from such different places 
religiously. But able to experience something together and not need to talk about it necessarily but knowing that we were all on the same page. Student

These examples show how deep and meaningful the student relationships became and how instrumental a positive group can be for helping students understand what they are experiencing.

One interesting phenomenon that emerged when coding the students' descriptions of their interactions with each other is that they may be learning about their own identity and culture and consequently expanding their worldviews by interacting with students on the program with different value systems than theirs with whom they would not interact on their home campus. Students describe this diversity as follows:

The time I've talked about the most, so is probably my favorite memory, is I had a long conversation with two people on the trip who I couldn't be more different from. We are very different people. We have different beliefs, different majors, I would have never talked with someone like her in real life, you know what I mean? Student

Everyone had such different backgrounds: academics, because there were some science-y people, I'm microbiology, but then someone was family social science and someone was global studies, and someone was physiology. So you just get all these different perspectives.

\section{Student}

In this next section the students explaining the importance and enduring quality of their friendships made during their instructor-led program. The interviews took place five to six months post program.

We are still close. We get together like once a month as a whole group and my roommate from the trip, you know you have to do those surveys from what you want from a roommate? Both of us wrote like multiple paragraph descriptions of "this is what I'd like and this is who I am". And we got matched and it was exactly what we had asked for and we are like best friends now. Which I really needed a girlfriend on campus. That was super special.

\section{Student}

It was weird being the only first year student. I was the youngest and I didn't really know any of the older kids well. I felt more nervous than I probably needed to be... Now I still talk to a lot of them. We made our own facebook page it's a page where all of us talk to each other still. We all keep in contact, so I made some of my good friends on that trip. Student

We got along great. We still get together here. We are getting together next weekend. We were all very well knit together. We didn't have any technology. We couldn't use the internet or cell phones so you had to like each other! Student

It was hard to be selective with this section as there were so many strong examples of the students bonding, processing, and enjoying each other's company as they journeyed through their programs together. A positive group dynamic was brought up in the literature review as key to allowing students to make meaning of their experience in a safe, supportive environment. The importance of peer-to-peer processing was not discussed in the literature, perhaps because there is such a focus on integration with local culture within education abroad. As this section illustrates, the group was an important part of these students' experience and did help them to unpack what they 
were going through. The diversity of the groups allowed students to understand their own identity better which is important for gaining cultural sensitivity. The act of making and keeping friends can be an enduring impact from the students' short-term program experience.

Yet, peer-to-peer processing should never replace the role that the instructor plays in guiding the students through their experience. Instructors should check in with the group regularly on incidents that are occurring outside and inside the structure of the program to ensure that the cultural understanding that the students reach is based on their own perspectives expanding to "see" the other and other value systems rather than coming to the conclusion that because experiences do not fit into their American value matrix they are somehow wrong. Although the examples found in this study of students guiding other students were positive, we have heard reports from instructors when peer-to-peer processing is negative and derailed the health of the group. Peers are going off their own limited experience, while an instructor should be able to draw from several different experiences, a much broader perspective, and ideally knowledge of intercultural learning.

\section{Facilitation and Instructor Philosophy}

Frequent and spontaneous facilitation emerged as the most important variable to guide students' intercultural learning. The three groups with the most student pre-to post-IDI gains all incorporated this process holistically into their programs. All three of these instructors also philosophically believed in the importance and the value of intercultural learning. These two variables both need to be present for the transformative process to best occur. Those who valued intercultural learning, but didn't facilitate learning moments, did not achieve high IDI pre to post gains.

Facilitation on high IDI change groups often occurred "in the moment". The instructors and students on these programs discussed moving content in order to process. Those that did focus on the tensions that were occurring when students were experiencing a critical incident reported that it was crucial to address the tension first, before continuing with content, since students would become focused on the tension and would not tend to the content. As students' perspectives widen regarding their own value systems and assumptions, they were better able to comprehend course content topics with more sophistication and often from multiple perspectives. Following are two excerpts from the interviews. The first two come from a high IDI gain program with strong facilitation, followed by quotes from a lower gain program where there was a lack of facilitation.

I was like, if you think about it, if you put yourself into someone else's shoes who this is, the way that they make money. Any little thing that will give them an edge to make more money, you would probably do that too. I'm not saying it's right, but you can see why anything that might give you the edge to make a more money it might be something that you'd be willing to do. Instructor

I think we all appreciate the fact that the instructor spent a lot of time with discussion. Even if it meant that we talked about the chapter two reading less, because she understood the importance of cultural understanding. She prioritized that over last night's reading. Because that's stuff that you can do in a classroom. But the cultural stuff you have to do in country. And she was very good at listening and trying to help us see something in a different light...she kind of like turns the tables on you. Student describing above instructor 
The instructor wouldn't really help us [with the culture] but would give us knowledge on what he's experienced. The instructor would be like, you need to experience this on your own to form your own opinion. That's how the instructor did it; pretty much push us into water to make us swim. Personally I wasn't that, it wasn't that hard on me because I was open to everything. I don't know about others. Student from low facilitation program

This same student went on to say:

It was difficult seeing the third world country straight on. You always hear about people in the third world starving or begging but to actually see it and have them be there, it kind of hurt. There would always be beggars coming up to you asking for money and that made me a little distraught. We didn't talk about this as a group because I think that is just normal. We didn't talk about it because that's what the instructor expected. I didn't expect ...I expected it but not quite what I felt. Student

This student put on a strong face by saying 'it was not hard on me' not to talk about these things, but then goes on to state that he was 'hurt' and 'distraught' indicating that debriefing would have helped this student to contextualize the experience.

\section{High Challenge Destinations and Related Challenges}

Although not conclusive from the data gathered in this study, there is some evidence that a high challenge program and/or destination can achieve greater intercultural learning gains, but only when accompanied by strong, active facilitation along with a basic introduction to intercultural development frameworks. The two programs with the highest IDI change score gains were challenging with high facilitation. The program with the highest IDI score change reported the most challenging situations such as witnessing wife abuse in the street and at least three incidents of female students being groped. The program with the third highest IDI gains was low challenge with high facilitation.

The program with the lowest IDI change score (they regressed slightly) was a low challenge destination with low facilitation reported. Although this instructor philosophically valued intercultural learning, the push to continually see and process difference was not present. Another instructor on a program to a low challenge destination had high facilitation skills and was constantly challenging his students to see difference. Below are two examples of instructor facilitation from programs to low challenge destinations. The first quote is from a program with high IDI score change, the second is from a low IDI score change program.

One of the things is a reflection that I intentionally did, I said if you run into issues whether it's with a local or another student or somebody else ask yourself what's going on here? I'm clearly ticked off, or challenged or maybe I'm enthralled, but I'm feeling something I didn't feel before, why? Why am I? Let's analyze it and try to get down to what's going on here and then what happened that is different here that made me feel that way, good or bad and then why do you think it is that way here? I tell them that that is what I want in their journals and in their guided reflections. Instructor

The journal could be about their own reflections and intercultural part or it could be academic, I had many who were afraid of that side of themselves, so to make them not as uncomfortable, it could be a reflection on their academic experience. Instructor 
On low challenge programs there needs to be facilitation to guide students to see the difference and feel the discord in order for perspective shift to occur.

\section{Local interaction}

All programs reported some level of interaction with host-country locals. This is an important element to all study abroad programs. It can be difficult to incorporate formally, thus informal interactions such as through sports or meals should be considered in program design. Interviewing locals was impactful for students in this study.

The programs with the second and fourth highest mean student pre to post IDI gains reported the most interaction with locals. The program with the highest IDI gains reported medium interaction and the program with the third highest IDI gains students reported having difficulty meeting locals. As the top three programs for pre- to post-IDI gains reported high facilitation and the program with the fourth highest IDI gains had low facilitation it may be the high contact with locals on this program contributed to the students' IDI gains. Following are two positive yet distinct examples of interactions with host-country locals from students. The first is from a class activity where the student clearly experiences a different way of dealing with patient care that caused her to compare this practice with what she knows from the U.S. The second describes informal interaction, but is significant as it took place daily and the student reported making "friends" an important element in social contact theory (Pettigrew \& Tropp, 2006).

There was one day I went to a hospice care center and then we did a home visit to a man that had esophagus cancer. They were seeing him because he wasn't taking his medicine. So not only did they counsel him, it was not only medical. They explained it that they also do psychological counseling, emotional counseling. They are very spiritual and so we ended with a prayer. They don't just focus on the science. It's very holistic... I think that was very helpful to have someone come to your own home, so the comfort of your own home is important. Student

We got to be really good friends with the cook and the cooks helper Bob (says it again in local accent). We would play soccer daily at 5 or 5:30 when everybody is done working we would play soccer with them. Student

\section{Instructor: Knowledge of Destination, Local Language, IDI Score}

Our data suggest that high instructor host-country knowledge is not necessary to effect student intercultural development. Of interest, the instructors with low or medium knowledge of their hostcountry led the programs with the highest gains. In this study low knowledge means that the instructor never lived in the country, had visited on a limited basis, and did not speak the language at all or well. This may indicate that an instructor with less host-country knowledge is noticing difference more frequently than those with high knowledge and talking about this difference with the students.

Instructors' IDI score was not significant in this study as shown by the -.29 correlation coefficient on the Pearson's correlation coefficient. The range in scores was from 120 to 144 or from Acceptance to high Adaptation. The lack of variance in leader IDI scores as all had strong intercultural sensitivity on the IDI makes this variable invalid for this study. It is of note that only 
one of the four instructors with an IDI score in Adaptation had students who made significant gains on the IDI.

\section{Impact}

This section takes a broad look at how students are impacted by instructor-led programs. Students describe increasing their self-awareness, a crucial first step in culture learning. A common theme was changing or adding a major or minor. Students often felt pride that they rose to the challenge of their study abroad program. They liked that they now had this experience as part of their identity. This empowerment manifested as confidence and a belief that they could now conquer other challenges. Below are three categories of student change: cognitive, academic, and confidence.

Below students discuss how their instructor-led experience led them to view ideas, behaviors and themselves in a new way.

Just the ability to talk to people who are different than me, study abroad does that in general exposing you to realizing that there are different perspectives and then what was true about the Camino you were able to directly be engaged with it and able to experience those different ways of thinking, and different cultures, and different definitions of success and different definitions of love and experience that in a new place every day. Student

I changed in gaining the experience. Personally I changed in more so putting my shoes in other people's shoes. I thought I did that before but now I do it more. All those people in Cusco who, they are making a living. Their daily decisions how they are like ---even in Pilcopata how the shop owners are selling stuff and making food. I thought hey that's a happy life. It can be a happy life depending on what you make of it. Most of them were happy. I was like wow-it's a different way of thinking. Student

This section illustrates how impactful the instructor-led programs were for students to understand themselves better and realizing what academic focus was the most important to them or that for which they were most suited (also quoted in Language section).

Originally before the trip I was just going to get my Pharm-D. But after the trip, especially going to Otsuchi, I've decided to go for my Pharm-D, and MPH. because I want to do more to help with disasters like the tsunami because they don't get enough help. That's something I would have never considered before this trip. It's really showed me something that I didn't know I loved. Student

My major is computer science. My minor is now Italian. I didn't declare it until after I came back. Student

That's where [on my program] I learned everything about sustainability and I changed my major to sustainability studies. I'm currently a materials engineering. Student

This section holds quotes from students who have gained confidence and greater self-awareness.

It definitely changed me. I think after going there and not knowing anything but being able to experience so much it helped me gain a lot of confidence. Student 
But honestly I learned a lot about myself, as well, of what I was capable of and my independence level, my comfortability in a lot of different settings. That opened up a lot of ideas or windows into what I can do now. I'm just going with the flow and just saying hey I can do this now, I can figure this out. I can live in a foreign country, you know just problem solving by myself. It gave me a lot of those little skills. That I had but didn't really know I had but it exposed them. So I would honestly say I learned more about myself during this time than almost anything else. A lot of people depending on how much you push yourself or go out of your comfort zone that's how much you're going to learn. Student

I would say that that [the program] changed me even in just the three and a half weeks. I had a really awful first year of college and that totally redeemed everything about it. I went as a freshman... The way I've changed is like having really lost touch with myself and then finding myself again on that trip, knowing that I can find myself again has been really huge for me. If I ever feel myself drifting, I know that place is possible. It does exist. Student

The changes described by these students are profound. They describe changing degree plans, perspectives, habits, and having a more sophisticated view of their place in the world. One student met relatives he did not know he had, and is now planning to live and work in his host-country. All the students interviewed discussed at least one and usually more impactful outcomes from their time abroad.

There are many factors that could influence this type of change, most that have been discussed in detail in other sections of this paper. For many students instructor-led programs are their first time away from the known environment of their own country, family, and friends. Either formally or informally the students in this study recalled having time to reflect on who they were. These students were forced into new peer groups that they did not choose, which opened their minds to other values from within the group. Most importantly some students reported witnessing other ways of living and other value systems that made them reflect on how they live their lives and why they do what they do. The students that made that cognitive shift often discussed making behavioral changes once they have been exposed to a different value system and had time to consider that maybe this behavior was preferable to their previous responses in certain situations.

This does not mean that any instructor-led program will cause this type of transformation. All the instructors in this study had at least basic training on the theories and facilitation of intercultural learning. Students who attended orientation had a foundational grounding in intercultural frameworks and a basis for understanding their own identity. Although there were different levels of reflection and debriefing each of these programs provided the opportunity for both in some form.

\section{Limitations}

The large scope of this study is a limitation as eight programs were analyzed in seven different locations. This choice meant many different variables and may have impacted the weak regression results. Conversely, this provided a lot of rich data in the interviews.

The student sample for the interviews is a practical sample because it was difficult to get any students in to be interviewed. The interview population does not demographically represent the whole population as out of the fourteen interviewees six are males (males are about $25 \%$ of the whole population for this study and in national study abroad statistics), five are at the end of their 
freshmen year, and four are students of color. All fourteen students who came in were happy about their experience abroad. This is a limitation of this study indicating that only those who had a successful program were interviewed. That said, painful or difficult situations also surfaced and were discussed in the interviews. The similarity of some of these comments across programs may make it possible to attribute some personal change to much of the population on these instructor-led programs.

A large limitation is that not all students who participated in the programs took the pre post IDI. This meant very small sample sizes on some programs. The three programs with the smallest sample sizes also made the least amount of IDI gains.

\section{Discussion \& Next Steps}

Effective short-term, instructor-led study abroad programs can maximize the intercultural learning opportunities these immersive experiences offer for student intercultural development. To do so, they require a basic intercultural framework/foundation and a commitment from the instructor to engage students in surfacing the cultural challenges they encounter. The qualitative and quantitative data from this study support the assertion that intercultural gains can be made in shortterm, instructor-led programs and that instructor-led programs are different from non-instructor led programs. A key finding of our research is that frequent and spontaneous facilitation by instructors has a strong impact on achieving intercultural gains in students. The most effective instructors are those who create a safe place to debrief, where students can explore cultural challenges that can serve as disorienting dilemmas and become the catalysts for developing intercultural competency, the dependent variable we investigate in this study.

To maximize the potential for intercultural growth, instructors should be trained to understand the value of intercultural learning for their students and on how best to facilitate this while in country. Yet, the most important factor that emerged in this study is that the instructor must support and guide students through the incidents of cultural discord, in order to achieve the values and assumptions introspection that is necessary for the perspective shift required to enhance intercultural sensitivity.

Our data support that it may be beneficial to design programs to include language learning and interaction with locals. Students reported an increased interest in language study in those programs that included some level of language learning, however brief, while abroad. Interestingly, the data indicates that students with no prior host country language learning exhibited the most significant IDI gains. Students reported that interaction with locals was highly satisfying. There is some evidence that meaningful interaction with locals increased students' intercultural sensitivity.

Instructors who intentionally supported their group to achieve a healthy intra-group dynamic were more successful in increasing student intercultural gains. For the students, peer-to-peer processing was highly valued. Students reported learning about different values and beliefs through deep discussion with other students on the program, students they would not normally have connected with on campus. This points to a need to intentionally and constructively exploit group relationships on instructor-led programs where intercultural competence gains are an identified 
outcome. While this is counter to much education abroad literature that focuses on immersive practices (e.g. homestay), it seems strikingly relevant for short-term, instructor-led programs.

In addition to creating a safe place to process cultural challenges and immediate, frequent debriefs, three supporting themes emerged: intentionality, challenge, and close contact with the instructor. Instructors who were the most intentional when debriefing (often encouraging a nonjudgmental attitude and withholding their own values assumptions as issues were discussed) had greater success with positive IDI movement. These faculty frequently asked students to consider "why" something/action may have value for the host culture and "what" that value might be. Our study suggests that challenge plays an important role. In programs where there wasn't enough cultural challenge reported, there wasn't as much mean pre- to post-IDI movement. Students need to be confronted with their host culture at an intimate level in order to feel the tension, then be supported by their instructor to make meaning of the situation. Failure to do so neglects the opportunities of intercultural learning and student development, while increasing the likelihood that cross-cultural misunderstandings may subvert the intended content of the course and encourage reliance on stereotypes to bridge the experienced cultural confusion.

This study shows that there is a distinct difference in how intercultural learning occurs on an instructor-led program compared to a semester program. The instructor needs to be viewed as a prime source for intercultural mentoring, and students need to be offered an introduction to intercultural frameworks and tools. Our study shows that with intentional debriefing and basic intercultural knowledge, the instructor plays a large role in helping students to achieve intercultural learning gains. The group needs to be fostered and seen as a positive source where intercultural learning can occur with guidance. Although females made slightly higher intercultural learning gains than males, the difference was not as high as reported on some studies focused on semester length programs. This may mean that the extra mentoring provided to males on the instructor-led model aides their ability to integrate the intercultural challenges.

The interviews unintentionally uncovered multiple cases of sexual harassment. This is an area that needs more research. We suggest discussing safe practices in pre-departure orientation as well as onsite. In addition, instructors should create a space where students feel comfortable communicating on any and all safety issues. Instructors and education abroad offices should be prepared to offer students additional services as necessary.

We suggest further research be done on instructor-led programs and the influence of interventions for this model. Current research often compares short-term, instructor-led programs with semester or year-long programs, rather than focus on the unique context of the instructor-led model. Our data indicate that more research should be done to understand the connection between language learning and growth in intercultural sensitivity on instructor-led programs. Having no hostcountry language proficiency seemed to have an important positive impact on student's intercultural gains in this study, but there was not enough data to fully understand why that might be.

This study demonstrates that instructor-led study abroad is powerful. It introduces students to concepts, practices, locations, people, lifestyles, and a side of themselves that many have never encountered. When this fast, immersive experience is well facilitated and the meaning of what the students are experiencing is authentically engaged, students are empowered and their perspectives 
can grow to encompass new ways of thinking they had not previously imagined. But the power of this experience (and attendant challenge) can go the other way too. Without proper support, students who come in contact with new practices, poverty, or different cultural norms from their own may to regress to employing stereotypes, feel shame for their privilege, and back away from experiences that provide opportunity for more interaction with diverse groups. This research suggests that effective instructor facilitation makes a critical difference in how the students will develop during and after an instructor-led program.

\section{References}

Allport, G.W. (1954). The nature of prejudice. Cambridge, MA: Addison-Wesley.

Anderson, P. H., Lawton, L., Rexeisen, R. J., \& Hubbard, A. C. (2006). Short-term study abroad and intercultural sensitivity: A pilot study. International Journal of Intercultural Relations, 30(4), 457469.

Bakalis, S., \& Joiner, T. A. (2004). Participation in tertiary study abroad programs: The role of personality. The International Journal of Educational Management, 18(5), 286-291.

Bennett, J. M. (2008). On becoming a global soul: A path to engagement during study abroad. In V. Savicki (Ed.), Developing intercultural competence and transformation (pp. 74-91). Sterling, VA: Stylus.

Bennett, M. J. (1993). Towards ethnorelativism: A developmental model of intercultural sensitivity. In R. M. Paige (Ed.), Education for the intercultural experience (pp. 21-71). Yarmouth, ME: Intercultural Press.

Bennett, M. J. (2004). Becoming interculturally competent. In J. Wurzel (Ed.), Towards multiculturalism: A reader in multicultural education ( $2^{\text {nd }}$ ed., pp. 62-77). Newton, MA: Intercultural Resource Cooperation.

Bennett, J.M. \& Bennett, J.M. (2003). Developing intercultural sensitivity: An integrative approach to global and domestic diversity. In D. Landis, J.M. Bennett, M.J. Bennett (Eds.), Handbook of intercultural training ( $3^{\text {rd }}$ ed., pp.147-165). Thousands Oaks, CA: SAGE Publications.

Castiglioni, I. (2013) Constructing intercultural competence in Italian social services and healthcare organizations: Pedagogical design, effectiveness research, and alternative visions for promoting ethnorelativism. Jyväskylä Studies in Humanities series, University of Jyväskylä, Finland.

Cisneros-Donahue, T., Krentle, K., Reinig, B, \& Sabol, K. (2012). Assessing the academic benefit of study abroad. Journal of Education \& Learning. 1(2),169-183.

Cranton, P. (1994). Understanding and promoting transformative learning. San Francisco, CA: JosseyBass Inc.

Deardorff, D. K. (2008). Intercultural Competence: A Definition, Model and Implications for Education Abroad. In V. Savicki (Ed.), Developing intercultural competence and transformation. (pp. 32-52). Sterling, VA: Stylus.

Dewey, J. (1916). Democracy and education: An introduction to the philosophy of education, New York, NY: Macmillan.

Douglas, C., \& Jones-Rikkers, C. G. (2001). Study abroad programs and American student worldmindedness: An empirical analysis. Journal of Teaching in International Business, 13(1), 55.

Dwyer, M. M. (2004). More is better: The impact of study abroad program duration. Frontiers: The Interdisciplinary Journal of Study Abroad, X (Fall), 151-163.

Engle, L. \& Engle, J. (2012). Beyond immersion the American University Center of Provence experiment in holistic intervention. In M. Vande Berg, R.M. Paige, \& K. Hemming Lou. (Eds.), Student learning abroad: What our students are learning, what they're not and what we can do about it. (pp.284-307). Sterling, VA: Stylus.

Hammer, M. R. (2011). Additional cross-cultural validity testing of the Intercultural Development Inventory. International Journal of Intercultural Relations, 35, 474-487. 
Hammer, M. R., Bennett, M. J., \& Wiseman, R. (2003). The Intercultural Development Inventory: A measure of intercultural sensitivity. In M. Paige (Guest Editor), International Journal of Intercultural Relations, 27, 421-443.

Hofstede, G., Hofstede, G. J., \& Minkov, M. (2010). Cultures and organizations: Software of the mind (3 ${ }^{\text {rd }}$ ed.). USA: McGraw-Hill.

Institute of International Education. (2014). Fast facts. Open Doors Data. Retrieved from http://www.iie.org/Research-and-Publications/Open-Doors/Data/Fast-Facts.

Institute of International Education. (2014). U.S. study abroad: Student profile. Open Doors Data. Retrieved from http://www.iie.org/Research-and-Publications/Open-Doors/Data/US-StudyAbroad/Student-Profile/2000-13

Institute of International Education. (2011). Press Release. U.S. campuses report that study abroad is rising. Retrieved from http://www.iie.org/Who-We-Are/News-and-Events/Press-Center/PressReleases/2011/2011-11-14-Open-Doors-Fall-Survey-Study-Abroad

Kitsantas, A. (2004). Studying abroad: The role of college students' goals on the development of crosscultural skills and global understanding. College Student Journal, 38(3), 441-453.

Lorenz, K., White, M., \& Anderson, C. (2012). Using the IDI to Debrief on Instructor-led Programs. Presentation, Minneapolis, MN.

Meacham, J. \& Gaff, J. G. (2006). Learning goals in mission statements. Liberal Education 92(I), 6-13.

Medina-López-Portillo, A. (2004). Intercultural learning assessment: The link between program duration and the development of intercultural sensitivity. Frontiers: The Interdisciplinary Journal of Study Abroad, X (Fall), 179-199.

Mezirow, J. (2000). Learning to think like an adult: core concepts of transformation theory. In J. Mezirow (Ed.), Learning as transformation: Critical perspectives on a theory in progress. (pp. 3-33). San Francisco, CA: Jossey-Bass, Inc.

NAFSA. (2005). The Lincoln commission report. Retrieved from http://www.nafsa.org/uploadedFiles/NAFSA Home/Resource Library Assets/CCB/lincoln_commis sion report(1).pdf?n=6097

Nam, K. (2011). Intercultural development in the short-term study abroad context: A comparative case study analysis of global seminars in Asia (Thailand and Laos) and in Europe (Netherlands). (Unpublished doctoral dissertation from University of Minnesota, 2011). Retrieved from http://conservancy.umn.edu/bitstream/104702/1/Nam_umn_0130E_11866.pdf

Pedersen, E. R., Cruz, R., LaBrie, J., \& Hummer, J. (2011). Examining the relationships between acculturation orientations, perceived and actual norms, and drinking behaviors of short-term American sojourners in foreign environments. Prevention Science, 12 (4), 401-410.

Pedersen, E. R., Neighbors, C., Lee, C. M., \& Larimer, M. E. (2012). Not all those who wander are lost: Examining the impact of sojourner adjustment and drinking motives on alcohol consequences experienced by Americans studying in foreign countries. Journal of Studies on Alcohol \& Drugs. 73(6). 1005-1015.

Pedersen, P. J. (2009a). Teaching towards an ethnorelative worldview through psychology study abroad. Intercultural Education, 20 (S1-S2), S73-S86.

Pedersen, P. J. (2009b). Assessing intercultural effectiveness outcomes in a year-long study abroad program. International Journal of Intercultural Relations, 34, 70-80.

Pettigrew, T. F. (1998). Intergroup contact theory. Annual Review of Psychology, 49, 65-85.

Pettigrew, T. F. \& Tropp, L. R. (2006). A meta-analytic test of intergroup contact theory. Journal of Personality and Social Psychology. 90 (5), 751-783.

Rexeisen, R., \& Al-Khatib, J. (2009). Assurance of Learning and Study Abroad: A Case Study. Journal of Teaching in International Business, 20 (3), 192-207. http://dx.doi.org/10.1080/08975930903099077

Sanford, N. (1966). Self \& society. New York: Atherton Press.

Stephenson, S. (2002) Beyond the lapiths and the centaurs: Cross-cultural "deepening" through study abroad. In W. Grünzweig, N. Rinehart (Eds.), 'Rockin' in Red Square: Critical approaches to international education in the age of cyberculture (pp. 85-104). LIT, Münster 
Vande Berg, M., Connor-Linton, J., Paige, M. R. (2009). The Georgetown consortium project: Interventions for student learning abroad. Frontiers: The Interdisciplinary Journal of Study Abroad, XVIII, 1-75.

Vande Berg, M., Quinn, M., \& Menyhart, C. (2012). An experiment in developmental teaching and learning abroad. In M. Vande Berg, R. M. Paige, \& K. Hemming Lou. (Eds.), Student learning abroad: What our students are learning, what they're not and what we can do about it. (pp.383-410). Sterling, VA: Stylus.

Younes, M. N., \& Asay, S. M. (2003). The world as a classroom: The impact of international study experiences on college students. College Teaching, 51 (4), 141-147. 


\section{Appendix}

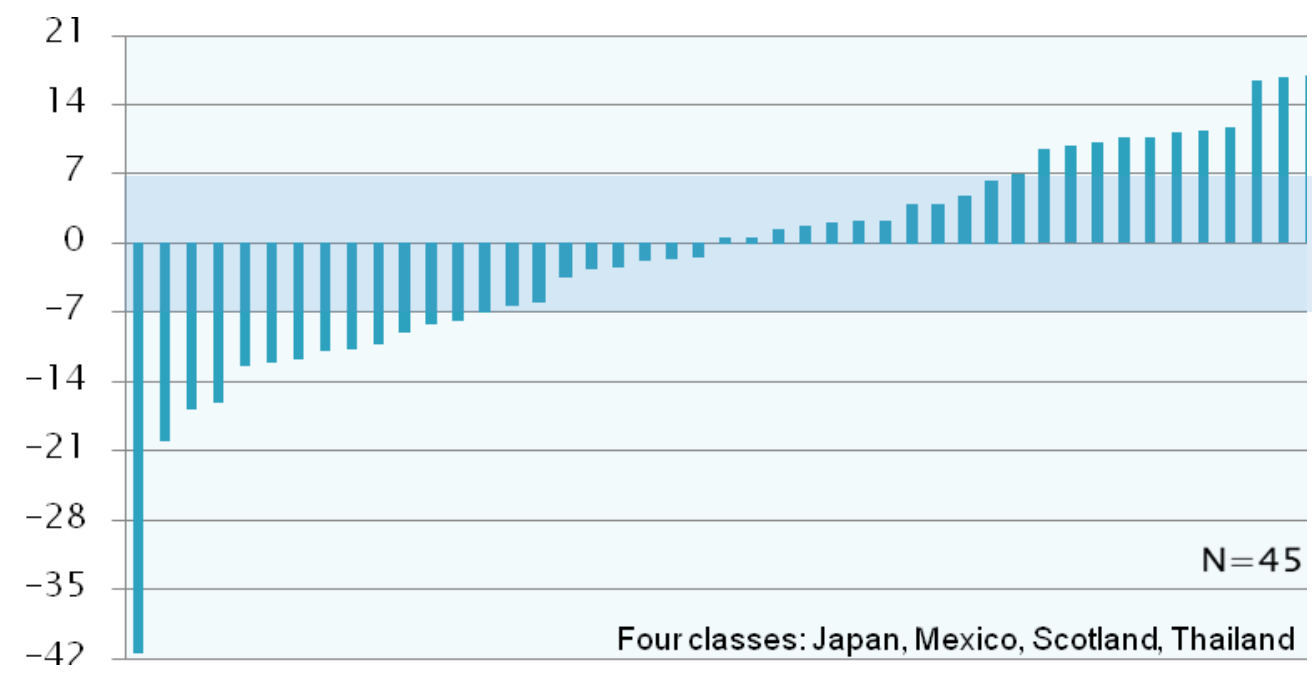

Chart 1. This chart displays the control group difference in pre-post IDI scores for the control group. A difference of \pm 7 or more points reflects a significant change in orientation.

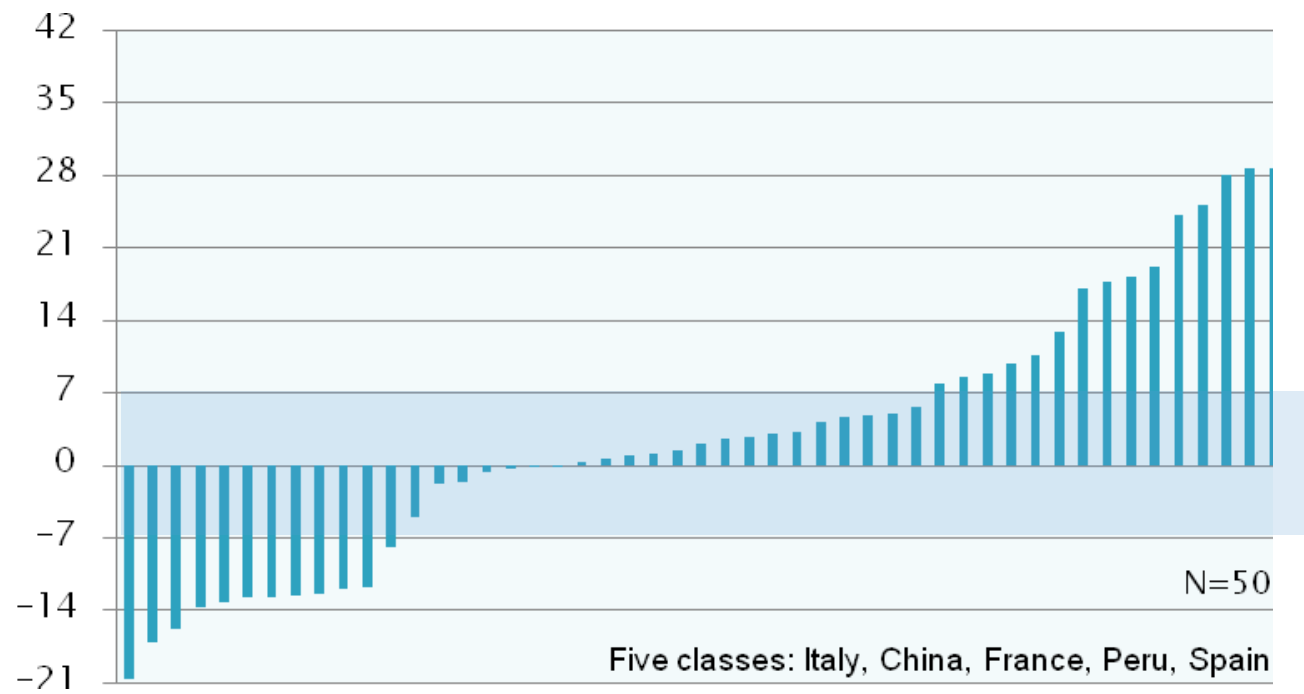

Chart 2. This chart displays the difference in pre-post IDI scores resulting from adding a pre-departure presentation of the group IDI score, a basic introduction to intercultural competence frameworks, and cultural self-reflection for students. A difference of \pm 7 or more points reflects a significant change in orientation. 


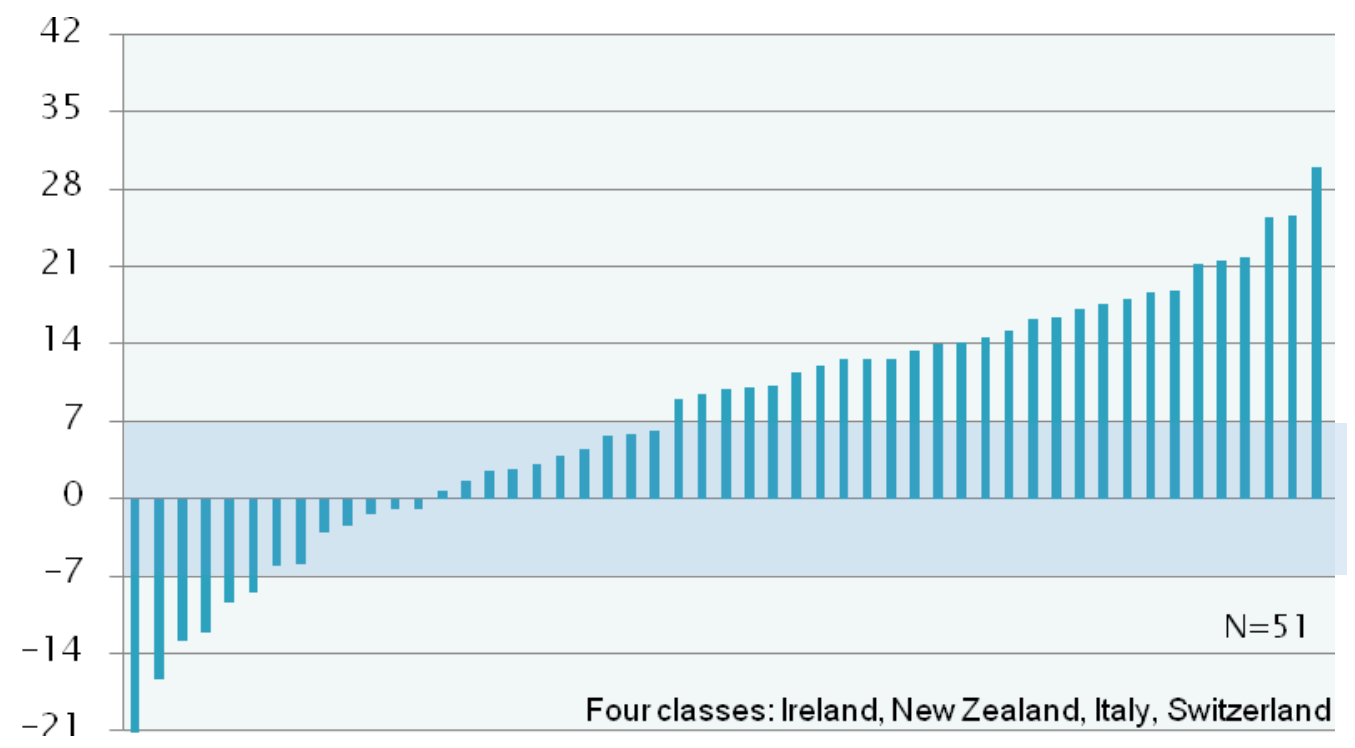

Chart 3. This chart displays the difference in pre-post IDI scores resulting from adding a pre-departure individual feedback session for each participant, a group IDI presentation, a basic introduction to intercultural competence frameworks, and cultural self-reflection for students while abroad. A difference of \pm 7 or more points reflects a significant change in orientation. 